EDITORIAL

\title{
Pharmacy Leadership during the COVID-19 Pandemic
}

Peter J Zed

$\mathrm{O}^{n}$ March 11, 2020, the World Health Organization declared a pandemic caused by the severe acute respiratory syndrome coronavirus 2 (SARS-CoV-2), an infection now known as coronavirus disease or COVID-19. ${ }^{1}$ Since then, the world has undergone unprecedented disruption and change, and the impact on every aspect of our lives has been tremendous. The health care system in which we practise as pharmacists has been challenged to respond. Together with other health care providers, we have been called upon to provide swift and necessary leadership in response to the many rapidly changing issues that have emerged. ${ }^{2}$ Leadership in pharmacy has been demonstrated in many ways during this pandemic, calling upon and highlighting our expertise, experience, capabilities, and resilience to do what is necessary in caring for our patients, ourselves, and our system. Although space does not permit a comprehensive survey, I would like to illuminate a few areas where our profession has tackled this pandemic through leadership in clinical care, collaboration, education and research, and communication.

As we prepared for what became the pandemic, planning for anticipated and uncertain impacts in our system has been a monumental challenge. Health and human resources planning has been front of mind for senior pharmacy administrators for months. The deployment or redeployment of staff and appropriate expertise has been critical, and many health authorities have developed flexible plans that are permitting our pharmacists and team members to provide clinical care to all patients. Attention to pandemic-specific clinical practice issues has been needed to ensure maintenance of the drug supply, especially medications that will be in greater demand during the pandemic. Planning for procurement of these essential medications, should demand outstrip supply, was essential. In addition, how medications are prepared, stored, and distributed at the system and institutional levels required careful consideration. The use of experimental therapies has also created challenges in clinical care. Drugs that have not undergone appropriate evaluation in relation to COVID-19 could have unintended consequences, including uncertainty about their efficacy and safety, as well as limiting access for patients who need them for previously approved indications. ${ }^{3}$ It is indeed tempting to consider unproven therapies during a pandemic that is causing significant morbidity and mortality. However, the pandemic should not force

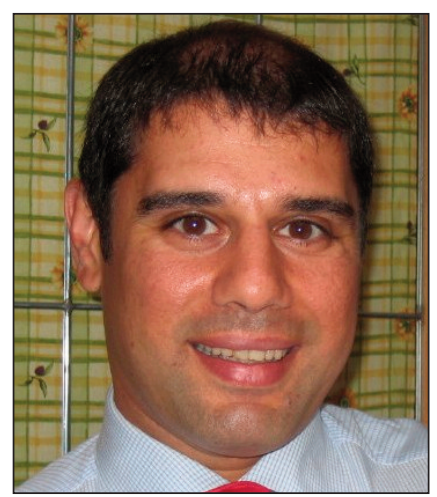
us to choose between rapid, premature adoption of unproven therapies and adequate evidence to support efficacy and safety. ${ }^{4}$ Finally, how we conduct clinical care has changed, the most striking difference being the move to virtual care, to keep both patients and health care team members safe. Regulatory bodies and provincial heath organizations have provided guidance and support in the provision of virtual care, and many practices outside the acute care environment have shifted entirely to virtual care..$^{5-7}$

Collaboration on many levels has been required to manage this pandemic. The collaborations between public health organizations and the many stakeholders in health care have been obvious. In addition, there have been collaborations between organizations and stakeholders within our own profession, in a wide range of critical areas, including personal protective equipment (PPE), supply chain, regulation for safe dispensing and administration, clinical care, and health and human resources management. Some of these joint endeavours have resulted in appropriate advocacy for the drug supply, while others have focused on the availability of and education about proper use of PPE for pharmacy team members across the care continuum. Appropriate selection and use of medications, appropriate timing of doses and reduction in dosing frequency, and deprescribing of unnecessary medications are all areas where 
pharmacy has worked in concert with other disciplines in providing leadership to preserve the drug supply, valuable PPE, and ultimately the safety of all members of the heath care team. I hope that after the crisis has passed, we will carry lessons from this collective leadership and collaboration into the postpandemic era.

Throughout the pandemic, a staggering amount of information is being generated, and keeping up with the literature would be a challenge if not for the tremendous leadership of many in the field of pharmacy. This leadership was evident within the first week of the pandemic, when the BC Branch of the Canadian Society of Hospital Pharmacists (CSHP) launched a webinar series, led by experts in their respective areas, to share current best evidence on emerging pharmacotherapy issues. ${ }^{8}$ The series has explored the use of nonsteroidal antiinflammatory agents, renin-angiotensin-aldosterone blockers, hydroxychloroquine, corticosteroids, and statins, as well as providing education about transmission, testing, and COVID19 considerations in special populations. Another webinar series, hosted by CSHP National, has provided further education for pharmacists and team members. ${ }^{9}$ While nearly all prior clinical and pharmacy practice research activities have been suspended, research related to every aspect of COVID-19 has been encouraged and supported. This has created an opportunity for pharmacists to provide research leadership, by shifting valuable resources and expertise to participate in and lead projects in both clinical and pharmacy practice. Leadership in education and research has been welcomed and timely, and has supported the development and application of best evidence in these times of uncertain, conflicting, and rapidly changing information.

Perhaps the most important aspect of leadership observed in recent months has been our ability to communicate significant and rapidly changing information. Since the pandemic was declared, our public health officials have provided daily updates to the public and health care administrators and providers. This process has set the tone for varied and regular communication, through various modalities, from our provincial associations, regulatory bodies, volunteer professional organizations, and academic institutions. ${ }^{9-12}$ For hospital pharmacists, the CSHP has been that voice and organizational leader, and I applaud the organization for its ability to mobilize its dedicated staff, volunteers, and expert members to ensure we have the information we need in this challenging time.

Leadership is always important, yet in recent years I have heard our profession question the future of leadership in pharmacy. It should not take a pandemic to propel our collective leadership into action, but I am proud of our profession and the shared leadership it has demonstrated recently. In particular, leaders at all levels within our profession should be commended for putting our patients and our people at the forefront. We will get through this together, and I am confident that the obstacles to be faced before this pandemic is over will be met with the same leadership we have shown to date. I challenge our profession to carry this momentum beyond the pandemic and-through our commitment, expertise, and dedication to excellence-to continue to lead, playing a critical role in our health care system and improving the heath outcomes of our patients.

\section{References}

1. WHO Director-General's opening remarks at the media briefing on COVID19 - 11 March 2020. World Health Organization; 2020 [cited 2020 Apr 26]. Available from: https://www.who.int/dg/speeches/detail/who-director-generals-opening-remarks-at-the-media-briefing-on-covid-19---11-march-2020

2. Herrera V, Finkler N, Vincent J. Innovation and transformation in response to Covid-19: seven areas where clinicians need to lead. NEJM Catalyst. 2020 Apr 16. Available from: https://catalyst.nejm.org/doi/full/10.1056/ CAT.20.0087

3. Rome BN, Avorn J. Drug evaluation during the Covid-19 pandemic. NEngl JMed. 2020 Apr 14. doi: 10.1056/NEJMp2009457

4. Clinical reference group recommendation: therapies for COVID-19. BC Ministry of Health, BC Centre for Disease Control; [updated 2020 Apr 20; cited 2020 Apr 26]. Available from: www.bccdc.ca/Health-ProfessionalsSite/Documents/Recommendation_Unproven_Therapies_COVID-19.pdf

5. Virtual medication history interviews and discharge education. ISMP Can Saf Bull. 2020 Apr 7 [cited 2020 Apr 26];20(2):1-3. Available from: https://www.ismp-canada.org/download/safetyBulletins/2020/ ISMPCSB2020-i2-VirtualBPMHDischargeEducation.pdf

6. COVID-19 virtual health toolkit. Provincial Health Services Authority (BC); [cited 2020 Apr 26]. Available from: www.phsa.ca/health-professionals/ professional-resources/office-of-virtual-health/covid-19-virtual-health-toolkit

7. COVID-19 guidance - providing virtual care to patients. Alberta College of Pharmacy; [updated 2020 Apr 6; cited 2020 Apr 26]. Available from: https://abpharmacy.ca/covid-19-guidance-providing-virtual-care-patients

8. COVID-19: what pharmacists know now series. Canadian Society of Hospital Pharmacists, BC Branch; [cited 2020 Apr 26]. Available from: https:// cshp-bc.com/covid-19-what-pharmacists-know-now/

9. Pharmacy practice: COVID-19. Canadian Society of Hospital Pharmacists; [cited 2020 Apr 26]. Available from: https:/www.cshp.ca/covid-19

10. COVID-19: information and resources. Canadian Pharmacists Association; [cited 2020 Apr 26]. Available from: https:/www.pharmacists.ca/advocacy/ covid-19-information-for-pharmacists/

11. Resources for coronavirus. Ontario Pharmacists Association; [cited $2020 \mathrm{Apr}$ 26]. Available from: https://www.opatoday.com/professional/resources/ for-pharmacists/tools-and-forms/coronavirus-2

12. Novel coronavirus (COVID-19). College of Pharmacists of British Columbia; [cited 2020 Apr 26]. Available from: https://www. bcpharmacists.org/covid19

Peter J Zed, BSC, BSC(Pharm), ACPR, PharmD, FCSHP, is Professor and Associate Dean, Practice Innovation, Faculty of Pharmaceutical Sciences, and Associate Member, Department of Emergency Medicine, Faculty of Medicine, The University of British Columbia, Vancouver, British Columbia. He is also an Associate Editor with the Canadian Journal of Hospital Pharmacy.

Competing interests: None declared.

\section{Address correspondence to:}

Dr Peter J Zed

Faculty of Pharmaceutical Sciences

The University of British Columbia

2405 Wesbrook Mall

Vancouver BC V6T 1 Z3

e-mail: peter.zed@ubc.ca 